\title{
Demography and Ethnography of Fertility Behaviour: A Study of Non-Industrial Population in India
}

\author{
Satyajeet Nanda \\ Council for Social Development, 53 Lodi Estate, New Delhi 110 003, India \\ E-mail: nsatyajeet@gmail.com
}

KEYWORDS FertIlity. Behaviour. Scheduled tribes. Verbatim.

\begin{abstract}
This is an endeavour to study the causal relationship between the women's behavioural factors and fertility in a more or less non-industrial rural population in an Eastern Indian state. It analyses the women's behavioural factors with regard to impact on fertility. The behavioural factors of women higher desired family size and longer perceived ideal birth interval has been consistently associated with lower fertility. For Scheduled caste population, the association of woman's correct knowledge about probable days of conception within menstrual cycle, with lower fertility gives impression that this knowledge may provide chance to the woman or couple to go for some kind of fertility control mechanism. The verbatim and incidents studied give impression that at one hand the child survival is at demand and in other hand there seem to have a need for access to controlled and intended fertility.
\end{abstract}

\section{INTRODUCTION}

Since many of the behaviours affect the actual practice regarding human fertility and even the biology of fertility, behavioural factors have been considered important in fertility research. In addition to its role as background factors, these have also been recognised as intermediate (Davis and Blake, 1956) factors of fertility and some even have perceived as proximate determinants of human fertility (Nag, 1962; Bongaarts, 1983 and 1993). Specific factors like knowledge and attitude have been key determinants of variability in fertility. It has been felt important to find out through micro level studies about the stages at which fertility attitudes are first formed and process through which attitudes crystallise into a definite desire to limit family size (Mari Bhat, 1993). The knowledge, attitude and practice of women as well as men directly or indirectly influence fertility. Again, these are affected by some other background factors like socioeconomic background, external intervention (program factors, culture contact) etc.

An inherent limitation in the study of fertility perception is that the responses to some extent are affected by the environment, socio-economic and psychological condition of the respondent at the time of survey. Possible influence of personal bias cannot be ruled out. So the response may vary by time and space. Even Page and Lesthaeghe (1981) have noted the responses as 'rather slippery pieces of information'. In some societies the very idea of individual control over fertility may be foreign, leading many respondents to answer that family size is 'up to God' or to make some similar objection. In such circumstances a numerical estimate of desired size, even if obtained, may have little meaning. In spite of potential difficulties the expressed desired family size in Third World countries is often compared with current fertility level. A desired size significantly below current levels is commonly taken as indicative of a latent desire for greater availability of facilities for family planning (Pressat and Wilson, 1985). Pillane and Ryser (1975) in a study on fertility knowledge, attitude and practice of males in Pittsburgh inferred that there is a strong association between parity and males' desired family size.

\section{DATA AND METHODOLOGY}

Against these backdrops the current paper endeavours to examine the nature and magnitude of association of the behavioural characteristics of women with fertility. For this study, data were collected from the 'Angul' district of Orissa, which had a comparatively higher proportion of scheduled caste (SC) and scheduled tribe (ST) population (Census of India, 1991). The currently married women of the age group 13 to 49 years were chosen as the respondents. A total of about 600 such women, 300 each from scheduled castes and scheduled tribes were interviewed in the sample survey. Besides 
quantitative data, some qualitative information on aspects like fertility preference, perception and practice regarding health and particularly on reproductive morbidity, conception period were collected. The data collection was carried out during July, 1997-February, 1998. Specific information has been elicited about their ideal and desired family size, birth interval and sex composition of the children, knowledge about family planning methods and probable period of conception within a menstrual cycle and fertility decision-making.

The variables mentioned above have been analysed from the direct questions of the women's questionnaire and some were rated. All the currently married women irrespective of children ever born (also infertile) have been considered for analysis. All the variables in the analyses are the current perception of the women except for the desired family size, which has been asked in the context of their beginning of family building process, that is 'just after marriage'. An ANOVA test has been carried out along with bivariate descriptive analysis of fertility level by different background as well as intermediate characteristics to examine the differential in variance. To find out the sole effect of each of the intermediate factors, controlling for other confounding factors (both independent variables and covariates), particularly the categorical variation in fertility (Frank et. al., 1973), the multiple classification analyses (MCA) were undertaken.

\section{ANALYSIS AND DISCUSSION}

\subsection{Women's Behavioural (Perception) Factors and Fertility}

From the study it was found that around 27 percent of all women feel a family size of 4 or more children to be an ideal condition and 10 percent could not report a specific number to this question (table 1). However, a little higher proportion of Scheduled tribe women as compared to Scheduled caste women (28 per cent Vs. 26 per cent) perceived a family size of 4 or more children to be ideal. A major chunk (60 percent) of the sample women perceived an interval of 2-3 years between the subsequent births to be ideal. Scheduled caste women in this regard were less in proportion than STs. Even twenty percent of all perceived a birth interval of 4 years or more as ideal. A higher proportion of scheduled caste women fall into this category.

Table 1: General behavioural characteristics of the sample women. (in percentage)

\begin{tabular}{|c|c|c|c|}
\hline Background characteristics & $\begin{array}{l}S C \\
(N= \\
300)\end{array}$ & $\begin{array}{c}S T \\
(N= \\
300)\end{array}$ & $\begin{array}{c}\text { Total } \\
(N= \\
600)\end{array}$ \\
\hline \multicolumn{4}{|l|}{ Perceived Ideal Family Size } \\
\hline Don't know & 10.7 & 9.3 & 10.0 \\
\hline $1-3$ & 63.62 & 63.0 & 63.3 \\
\hline $4+$ & 5.7 & 27.7 & 26.7 \\
\hline \multicolumn{4}{|l|}{ Perceived Ideal Birth Interval } \\
\hline Don't know & 15.7 & 14.7 & 15.2 \\
\hline $1 \mathrm{yr}$ & 2.05 & 5.0 & 3.5 \\
\hline $2-3 \mathrm{yrs}$. & 6.6 & 63.3 & 60.0 \\
\hline $4+$ yrs. & 25.7 & 17.0 & 21.3 \\
\hline \multicolumn{4}{|c|}{ Perceived Ideal Interval Between Marriage and First Birth } \\
\hline Don't know & 19.7 & 18.7 & 19.3 \\
\hline $1 \mathrm{yr}$. & 15.0 & 26.3 & 20.7 \\
\hline 2 yrs. & 44.0 & 37.3 & 40.5 \\
\hline $3+\mathrm{yr}$ & 21.3 & 17.7 & 19.5 \\
\hline \multicolumn{4}{|l|}{ Perceived Ideal No. of Sons } \\
\hline Don't know & 15.0 & 15.7 & 15.5 \\
\hline 1 & 40.1 & 19.7 & 29.5 \\
\hline 2 & 38.9 & 48.3 & 43.8 \\
\hline $3+$ & 6.0 & 17.3 & 11.2 \\
\hline \multicolumn{4}{|c|}{ Desired No. of Sons Just After Marriage } \\
\hline Don't know & 29.3 & 36.0 & 32.5 \\
\hline 1 & 33.0 & 17.3 & 25.2 \\
\hline 2 & 30.4 & 35.7 & 33.0 \\
\hline $3+$ & 7.3 & 11.3 & 9.3 \\
\hline \multicolumn{4}{|c|}{ Woman Takes Part in Fertility Decision } \\
\hline No & 25.3 & 21.3 & 23.3 \\
\hline Yes & 74.7 & 78.7 & 76.7 \\
\hline \multicolumn{4}{|c|}{ Know About Any Family Planning Method } \\
\hline Yes & 83.3 & 84.3 & 83.8 \\
\hline No & 16.7 & 15.7 & 16.2 \\
\hline \multicolumn{4}{|c|}{ Knowledge About Probable Period (Days) of Conception } \\
\hline Don't know/wrong & 92.3 & 90.3 & 91.3 \\
\hline Right & 7.7 & 9.7 & 8.7 \\
\hline
\end{tabular}

It was again found that overall 40 percent and relatively more SC women (65\% SC Vs. $55 \%$ ST) perceived an interval of more than one year between marriage and the first birth to be an ideal condition. Nineteen percent of all women could not report any specific period on this.

By sex composition of the children, it was found that 44 percent of all women perceived two sons to be an ideal composition and 11 percent reported more than 3 sons in the completed family to be an ideal situation. Compared to scheduled caste women, a higher proportion of scheduled tribe women perceived more sons in a family to be the ideal condition. Similar responses were observed regarding the desired number of sons at the beginning of family 
building process. Forty-two percent overall and again comparatively more ST women reported that they desired 2 or more sons at the beginning of family building process. With regard to the access to fertility decision-making, 77 percent of all and comparatively little higher proportion of scheduled tribe women reported to take part in fertility decision. So far as contraceptive knowledge is concerned, 84 percent of all reported to have some knowledge. Only 9 percent of all women reported a more or less correct probable period (days) of conception within the menstrual cycle of a woman. Comparatively little more ST women were found to have both these knowledge.

Information for a quick assessment of differentials in the ideal, desired and actual family size of the women and also their husbands are given in table 2 (a). The reported desired family size of both husband and wife was found to be lower than the actual number of surviving children which is again little lower than actual CEB and reported ideal family size. Comparatively, more schedule tribe women reported larger ideal and desired family size than scheduled caste women, but in practice their fertility level is slightly lower than the later.

The average actual fertility of women (mean CEB) by their behavioural factors is given in table 2(b). It was observed that those who perceived a larger family size to be an ideal condition were found to have higher fertility. This association persisted to be more significant in the middle age group women who belonged to scheduled tribe. A negative association of fertility with the women's perceived birth interval consistently emerged out in the bivariate analysis. A higher level of fertility was observed for the women who could take part in the fertility decision-making. This may be a result of the

Table 2 (a): Mean values of behavioural variables

\begin{tabular}{lccc}
\hline Variables & $S C$ & $S T$ & Total \\
\hline Woman's ideal Family Size & 2.57 & 3.09 & 2.83 \\
Woman's ideal Interval & 1.80 & 1.62 & 1.71 \\
between marriage \& first birth (yr.) & & & \\
Woman's Ideal BI (yrs.) & 2.72 & 2.47 & 2.60 \\
Woman's Ideal no. of sons & 1.43 & 1.73 & 1.58 \\
Woman's desired no. of sons & 1.26 & 1.43 & 1.35 \\
Woman's desired family Size & 2.08 & 2.11 & 2.09 \\
Husband's desired family Size & 1.87 & 1.73 & 1.80 \\
Total conceptions & 3.05 & 2.94 & 2.99 \\
Total living children & 2.33 & 2.22 & 2.28 \\
CEB & 2.82 & 2.77 & 2.80 \\
\hline
\end{tabular}

Table 2(b): Mean CEB by behavioural characteristics of the sample women.

\begin{tabular}{|c|c|c|c|}
\hline Variables & $S C$ & $S T$ & Total \\
\hline \multicolumn{4}{|l|}{ Ideal Family Size } \\
\hline Don’t know & 2.56 & $3.42^{\mathrm{b}}$ & 2.96 \\
\hline $1-3$ & 2.75 & 2.33 & 2.56 \\
\hline $4+$ & 3.10 & 3.23 & 3.17 \\
\hline \multicolumn{4}{|l|}{ Ideal Birth Interval } \\
\hline Don't know & $3.02^{\mathrm{c}}$ & 3.02 & $3.02^{\mathrm{b}}$ \\
\hline $1 \mathrm{yr}$. & 3.66 & 3.13 & 3.28 \\
\hline $2-3$ yrs. & 2.73 & 2.72 & 2.73 \\
\hline $4+\mathrm{yrs}$ & 2.83 & 2.64 & 2.75 \\
\hline \multicolumn{4}{|c|}{ Ideal Interval Between Marriage and First Birth } \\
\hline Don't know & 3.00 & 3.05 & $3.02^{\mathrm{a}}$ \\
\hline $1 \mathrm{yr}$. & 2.97 & 2.45 & 2.64 \\
\hline $2 \mathrm{yrs}$. & 2.54 & 2.94 & 2.72 \\
\hline $3+$ yrs. & 3.12 & 2.61 & 2.88 \\
\hline \multicolumn{4}{|l|}{ Ideal No. of Sons } \\
\hline Don't know & $2.60^{\mathrm{b}}$ & $2.89 * \mathrm{~b}$ & $2.75^{\mathrm{b}}$ \\
\hline 1 & 2.55 & 1.94 & 2.35 \\
\hline 2 & 3.15 & 2.80 & 2.95 \\
\hline $3+$ & 3.00 & 3.52 & 3.38 \\
\hline \multicolumn{4}{|c|}{ Desired No. of Sons Just After Marriage } \\
\hline Don't know & 3.12 & $3.33 * \mathrm{bc}$ & $3.24^{\mathrm{bc}}$ \\
\hline 1 & 2.31 & 1.76 & 2.12 \\
\hline 2 & 2.86 & 2.50 & 2.67 \\
\hline $3+$ & 3.72 & 3.41 & 3.53 \\
\hline \multicolumn{4}{|c|}{ Desired Family Size Just After Marriage } \\
\hline Don't know & 3.14 & $3.34 *$ & 3.25 \\
\hline 1 & 1.50 & 2.66 & 2.20 \\
\hline 2 & 2.35 & 1.70 & 2.12 \\
\hline $3+$ & 3.00 & 2.75 & 2.86 \\
\hline \multicolumn{4}{|c|}{ Woman Takes Part in Fertility Decision } \\
\hline No & $2.46^{\mathrm{b}}$ & 2.40 & $2.43 *$ \\
\hline Yes & & 2.87 & 2.91 \\
\hline \multicolumn{4}{|c|}{ Knowledge on Probable Period of Conception } \\
\hline Don't know/wrong & $2.81^{\mathrm{b}}$ & 2.79 & 2.80 \\
\hline & & 2.62 & 2.75 \\
\hline \multicolumn{4}{|c|}{ Know About Any Family Planning Method } \\
\hline Yes & 2.84 & 2.88 & $2.86 *$ \\
\hline No & 2.70 & 2.17 & 2.44 \\
\hline Total & 2.82 & 2.77 & 2.8 \\
\hline
\end{tabular}

Note: a refers to significant $\mathrm{F}$ value (at 90 per cent $\mathrm{CI}$ ) for age group 13-19 yrs.

b refers to significant $\mathrm{F}$ value (at 90 per cent $\mathrm{CI}$ ) for age group 20-34 yrs.

c refers to significant $\mathrm{F}$ value (at 90 per cent $\mathrm{CI}$ ) for age group $35+\mathrm{yrs}$.

* refers to significant $\mathrm{F}$ value (at 90 per cent $\mathrm{CI}$ ) for age group 13-49 yrs.

reverse causation and probably women at higher ages with more children have better access to decision making in the household. A negative association was found between the fertility and the correct knowledge of women about the probable period of conception in the women's menstrual cycle. But in case of scheduled caste women only, the factor, knowledge about the most probable period of conception showed a 
positive association with CEB.

The women who had some knowledge of family planning methods were found to have a significantly higher fertility. In case of the Scheduled Tribe women we observed a higher magnitude of variation. It was found that fertility tends to increase with the women's perceived ideal and desired number of sons and total children. This kind of a phenomenon was found to be more significant in middle age group women.

To causal relationship of the behavioural factors of women with fertility, multiple classification analyses were undertaken taking children ever born (CEB) as dependent variable, and women's selected behavioural variables along with the background factors as independent variables. The results show the sole effect of each factor on fertility, when the influences of other confounding (intermediate) factors are controlled. The variables woman's current age and marital duration were taken as covariates. The result of MCA for Behavioural characteristics for all (SC and ST) women are shown in table 3 . The grand mean $\mathrm{CEB}$ was found to be 2.80 . The multiple $\mathrm{R}^{2}$ of the MCA indicates that all the independent predictors together could explain only about 6 percent of the variation in the dependent variable CEB, whereas the independent variables along with the covariates could explain about 35 percent of the variation in CEB. It shows that this is necessary to include covariates such as woman's age and marital duration to know the real effect of the predictors after controlling the effect of covariates.

The unadjusted deviation of the category mean from the grand mean CEB is shown in col. 3 of the Table 3 . The variables desired family size just after marriage and ideal family size of the women were found to be the most important predictor variables affecting the fertility (CEB) since the deviation by category means were found higher. Eta values (col. 4) were also higher for this variable. Even after adjusting for other independent variables the category means (col. 5 ) for the variable desired family size remained almost same. Beta value (col. 6) also did not show much difference. However, when adjusted for other independents as well as covariates, the category means (col.7) and Beta value (col. 8) for the variable ideal family size showed drastic

Table 3: Summary result of Multiple Classification Analysis (MCA) for behavioural characteristics for all women. (Dependant variable $=$ CEB (continuous), Covariates- Woman's current age, Marital duration. Grand mean CEB- 2.80, N=600.

\begin{tabular}{|c|c|c|c|c|c|c|c|}
\hline \multirow{2}{*}{$\begin{array}{l}\text { Variables with category } \\
\text { (1) }\end{array}$} & \multirow{2}{*}{$\begin{array}{l}N \\
\\
(2)\end{array}$} & \multicolumn{2}{|c|}{$\begin{array}{c}\text { Unadjusted } \\
\text { Dev'n Eta }\end{array}$} & \multicolumn{2}{|c|}{$\begin{array}{l}\text { Adjusted for } \\
\text { Independents } \\
\text { Dev'n Beta }\end{array}$} & \multicolumn{2}{|c|}{$\begin{array}{l}\text { Adjusted for } \\
\text { Independents } \\
\text { + Covariates } \\
\text { Dev'n Beta }\end{array}$} \\
\hline & & (3) & (4) & (5) & (6) & (7) & (8) \\
\hline \multicolumn{8}{|l|}{ Ideal Family Size } \\
\hline Don't know & 60 & 0.17 & & -0.56 & & 0.01 & \\
\hline $1-3$ & 350 & -0.23 & & -0.02 & & -0.02 & \\
\hline $4+$ & 190 & 0.38 & 0.13 & 0.22 & 0.10 & 0.03 & 0.01 \\
\hline \multicolumn{8}{|l|}{ Ideal Birth Interval } \\
\hline Don't know & 91 & 0.22 & & 0.36 & & 0.22 & \\
\hline $1 \mathrm{yr}$. & 21 & 0.49 & & 0.69 & & 0.25 & \\
\hline $2-3$ yrs. & 360 & -0.07 & & -0.12 & & -0.10 & \\
\hline $4+$ yrs. & 128 & -0.04 & 0.06 & -0.05 & 0.10 & 0.07 & 0.06 \\
\hline \multicolumn{8}{|c|}{ Desired Family Size Just After Marriage } \\
\hline Don't know & 197 & 0.45 & & 0.49 & & 0.19 & \\
\hline $1-2$ & 158 & -0.67 & & -0.65 & & -0.35 & \\
\hline $3+$ & 245 & 0.07 & 0.20 & 0.03 & 0.20 & 0.07 & 0.10 \\
\hline \multicolumn{8}{|c|}{ Woman Take Part in Fertility Decision } \\
\hline No & 140 & -0.36 & & 0.00 & & -0.18 & \\
\hline Yes & 460 & 0.11 & 0.09 & 0.01 & 0.11 & 0.06 & 0.05 \\
\hline \multicolumn{8}{|c|}{ Knowledge on Probable Period of Conception } \\
\hline Don’t know/wrong & 548 & 0.00 & & 0.00 & & 0.00 & \\
\hline Right & 52 & -0.05 & 0.01 & 0.01 & 0.00 & 0.02 & 0.00 \\
\hline Multiple $\mathrm{R}^{2}$ & & & 0.061 & & & 0.349 & \\
\hline Multiple R & & & 0.247 & & & 0.591 & \\
\hline
\end{tabular}


change. For women who desired a higher family size (at the beginning of family building) and those reported a higher family size to be ideal had higher fertility i.e., the category mean increased to 2.87 and 2.83 respectively (col.7). Thus it showed that the real effect of the variables desired family size and ideal family size of the women were to raise the fertility. The variables such as perceived ideal birth interval of 2 to 3 years showed decline in category mean CEB both before and after adjusting for the independents and covariates. The variable proper knowledge of women about probable conception days in a menstrual cycle did not show any significant change in fertility, after adjusting for independents and covariates though little decline in fertility was found before adjustment.

The results of MCA for Behavioural characteristics for scheduled caste women are presented in table 4 . The grand mean CEB was found to be 2.82 . The multiple $\mathrm{R}^{2}$ was only 0.081 when the independent variables were included and it increased to 0.364 when the covariates were also included. This means, all the independent predictors together could explain about 8 percent of the variation in the dependent variable $\mathrm{CEB}$, whereas the independent variables along with the covariates could explain about 36 percent of the variation in CEB. This justifies the inclusion of covariates such as woman's age and marital duration in the sense that without controlling their effect the real effect of the predictors cannot be ascertained.

The unadjusted deviation of the category mean from the grand mean CEB is shown in col. 3 of the Table 4 . The variable 'desired family size of the women just after marriage' was found to be the most important predictor variable affecting the fertility (CEB) since the deviation by category mean was found higher. Eta value (col. 4) was also higher for this variable. After adjusting for other independent variables the category means (col. 5) for these variables changed. Beta value (col. 6) also showed big difference. When adjusted for other independents as well as covariates, the category means (col.7), and Beta value (col. 8) showed drastic change. For women who desired a higher family size had higher fertility i.e., the category mean increased to 2.95 (col.7). Thus it showed that the real effect of the variable 'desired family size of the women just after marriage' was to raise the fertility. The variable 'ideal birth interval' perceived by women as 2 to 3 years showed decline in category mean CEB both before and after adjusting for the independents and covariates. The correct knowledge of women about probable conception days in a menstrual cycle showed decline in fertility only after adjusting for both independents and covariates.

The result of MCA for Behavioural characteristics for scheduled tribe women are given in table 5. The grand mean CEB was found to be 2.77 . The multiple $\mathrm{R}^{2}$ showed that all the independent predictors together could explain about 9 percent of the variation in the dependent variable $\mathrm{CEB}$, whereas the independent variables along with the covariates could explain about 39 percent of the variation in CEB. It shows that this is necessary to include covariates such as woman's age and marital duration to know the real effect of the predictors after controlling the effect of covariates.

The unadjusted deviation of the category mean from the grand mean CEB is shown in col. 3 of the Table 5. The variables desired family size (at the beginning of family building) and ideal family size of the women were found to be the most important predictor variables affecting the fertility (CEB) since the deviation by category means were found higher. Eta values (col. 4) were also higher for these variables. After adjusting for other independent variables the category means (col. 5) for these variables changed little. Beta value (col. 6) also shows some difference. However, when adjusted for other independents as well as covariates, the category means (col. 7) and Beta value (col. 8) showed more change. For women who desired a higher family size and those who reported a higher family size to be ideal had higher fertility i.e., the category mean increased to 2.80 and 2.88 respectively (col.7). Thus it showed that the real effect of the variables desired family size and ideal family size of the women were to raise the fertility. The variables such as perceived ideal birth interval of 2 to 3 years showed decline in category mean CEB only before adjusting for the independents and covariates.

\subsection{Qualitative Information on People's Fertility Behaviour}

Regarding the fertility preference, some of the answers coming out of the FGDs, and informal interview of local people of the study 
Table 4: Summary result of Multiple Classification Analysis (MCA) for behavioural characteristics for SC women. (Dependant variable $=\mathrm{CEB}$ (continuous), Covariates- Woman's current age, Marital duration. Grand mean CEB- 2.82, N=300.

\begin{tabular}{|c|c|c|c|c|c|c|c|}
\hline \multirow{2}{*}{$\begin{array}{l}\text { Variables with category } \\
\text { (1) }\end{array}$} & \multirow{2}{*}{$\begin{array}{l}N \\
\text { (2) }\end{array}$} & \multicolumn{2}{|c|}{$\begin{array}{c}\text { Unadjusted } \\
\text { Dev'n Eta }\end{array}$} & \multicolumn{2}{|c|}{$\begin{array}{l}\text { Adjusted for } \\
\text { Independents } \\
\text { Dev'n Beta }\end{array}$} & \multicolumn{2}{|c|}{$\begin{array}{l}\text { Adjusted for } \\
\text { Independents } \\
+ \text { Covariates } \\
\text { Dev'n Beta }\end{array}$} \\
\hline & & (3) & (4) & $(5)$ & (6) & (7) & (8) \\
\hline \multicolumn{8}{|l|}{ Ideal Family Size } \\
\hline Don't know & 32 & -0.26 & & -1.85 & & -1.09 & \\
\hline $1-3$ & 191 & -0.07 & & 0.23 & & 0.18 & \\
\hline $4+$ & 77 & 0.28 & 0.08 & 0.19 & 0.31 & -0.01 & 0.18 \\
\hline \multicolumn{8}{|l|}{ Ideal Birth Interval } \\
\hline Don't know & 47 & 0.20 & & 1.10 & & 0.64 & \\
\hline $1 \mathrm{yr}$. & 6 & 0.84 & & 1.12 & & 1.08 & \\
\hline $2-3$ yrs. & 170 & -0.09 & & -0.28 & & -0.24 & \\
\hline $4+$ yrs. & 77 & 0.01 & 0.08 & -0.14 & 0.25 & 0.05 & 0.17 \\
\hline \multicolumn{8}{|c|}{ Desired Family Size Just After Marriage } \\
\hline Don't know & 89 & 0.32 & & & 0.57 & & 0.22 \\
\hline $1-2$ & 101 & -0.49 & & & -0.64 & & -0.34 \\
\hline $3+$ & 110 & 0.19 & 0.17 & 0.13 & 0.24 & 0.13 & 0.12 \\
\hline \multicolumn{8}{|c|}{ Woman Take Part in Fertility Decision } \\
\hline No & 76 & -0.36 & & -0.48 & & -0.35 & \\
\hline Yes & 224 & 0.12 & 0.10 & 0.16 & 0.14 & 0.12 & 0.10 \\
\hline \multicolumn{8}{|c|}{ Knowledge on Probable Period of Conception } \\
\hline Don't know/wrong & 277 & -0.01 & & -0.01 & & 0.02 & \\
\hline Right & 23 & 0.09 & 0.01 & 0.11 & 0.02 & -0.28 & 0.04 \\
\hline Multiple $\mathrm{R}^{2}$ & & & & 0.081 & & 0.364 & \\
\hline Multiple R & & & & 0.284 & & 0.603 & \\
\hline
\end{tabular}

Table 5: Summary result of Multiple Classification Analysis (MCA) for behavioural characteristics for ST women. (Dependant variable $=$ CEB (continuous), Covariates-Woman's current age, Marital duration. Grand mean CEB- 2.77, N=300.

\begin{tabular}{|c|c|c|c|c|c|c|c|}
\hline \multirow{2}{*}{$\begin{array}{l}\text { Variables with category } \\
\text { (1) }\end{array}$} & \multirow{2}{*}{$\begin{array}{l}N \\
\text { (2) }\end{array}$} & \multicolumn{2}{|c|}{$\begin{array}{l}\text { Unadjusted } \\
\text { Dev'n Eta }\end{array}$} & \multicolumn{2}{|c|}{$\begin{array}{l}\text { Adjusted for } \\
\text { Independents } \\
\text { Dev'n Beta }\end{array}$} & \multicolumn{2}{|c|}{$\begin{array}{l}\text { Adjusted for } \\
\text { Independents } \\
+ \text { Covariates } \\
\text { Dev'n Beta }\end{array}$} \\
\hline & & (3) & (4) & (5) & (6) & (7) & (8) \\
\hline \multicolumn{8}{|l|}{ Ideal Family Size } \\
\hline Don’t know & 28 & 0.65 & & 0.46 & & 0.96 & \\
\hline $1-3$ & 159 & -0.44 & & 0.28 & & -0.25 & \\
\hline $4+$ & 113 & 0.45 & 0.21 & 0.29 & 0.14 & 0.11 & 0.16 \\
\hline \multicolumn{8}{|l|}{ Ideal Birth Interval } \\
\hline Don't know & 44 & 0.25 & & 0.14 & & -0.07 & \\
\hline $1 \mathrm{yr}$. & 15 & 0.36 & & 0.54 & & -0.2 & \\
\hline $2-3$ yrs. & 190 & -0.05 & & 0.01 & & 0.03 & \\
\hline $4+$ yrs. & 51 & -0.13 & 0.06 & 0.08 & 0.06 & -0.03 & 0.02 \\
\hline \multicolumn{8}{|c|}{ Desired Family Size Just After Marriage } \\
\hline Don't know & 108 & 0.57 & & 0.49 & & 0.23 & \\
\hline $1-2$ & 57 & 1.02 & & 0.83 & & -0.52 & \\
\hline $3+$ & 135 & -0.02 & 0.25 & 0.04 & 0.21 & 0.03 & 0.12 \\
\hline \multicolumn{8}{|c|}{ Woman Take Part in Fertility Decision } \\
\hline No & 64 & -0.37 & & 0.42 & & -0.01 & \\
\hline Yes & 236 & 0.10 & 0.09 & 0.11 & 0.10 & 0.00 & 0.00 \\
\hline \multicolumn{8}{|c|}{ Knowledge on Probable Period of Conception } \\
\hline Don't know/wrong & 271 & 0.02 & & 0.00 & & -0.04 & \\
\hline Right & 29 & -0.16 & 0.02 & 0.04 & 0.01 & 0.37 & 0.05 \\
\hline Multiple $\mathrm{R}^{2}$ & & & & 0.091 & & 0.387 & \\
\hline Multiple R & & & & 0.302 & & 0.622 & \\
\hline
\end{tabular}


area are presented below.

- In an informal interview regarding longer interval between marriage and first birth or subsequent birth intervals almost in the absence of use of any spacing method of family planning by, various kinds of responses were obtained which are exactly translated from the local language as follows.

1. Situra scheduled tribe people of Nuamouza village, who are more or less illiterate and with a very lower socio-economic status reported,

i. For one or two years the body would not be strong, then how can anything come.

ii. The fruit can come only when the tree becomes ready to bear.

iii. How can we know.

iv. Sir, no more strength we have.

v. Sir, automatically.

vi. By own control.

2. Some local educated people, doctors and other medicine men reported,

i. This is natural.

ii. There is some problems with nutrition.

iii. Husband starts sexual intercourse before the wife is sexually stimulated, so the physiology doesn't lead to fertilisation of the egg.

iv. People don't have knowledge about the most probable days of conception within a menstrual cycle.

From majority of the above observations there comes an impression that the illiterate person perceive the fertility, solely as a function of individual's physiological capacity to bear like any other life-forms and is not controlled by human. However only one reported that it is controlled by them but how exactly was not reported. But literate people perceived the phenomenon of fertility as mainly of behavioural in nature.

- To the question asked to some couples presently in their reproductive span, "after the last child, you don't use contraceptives and both (spouses) stay together, then how there is no further pregnancy ?" The answers were,

i. Sir, from our side.

ii. God has given that much, what more is required.

- Even during survey for quantitative data to a question on whether they need any more children now, some people responded as,

I. If god gives then what we will throw them?

II. If we need whether the government will give us ?

- Regarding the motivation of female sterilisation, from village women and from the ANMs, different kinds of response came, viz.,

i. Some women reported that they are very angry on the ANM in their village, because she always tells them to go for sterilisation operation and never about any other methods. They reported that ANMs are not regular and some have never seen her.

ii. Few ANMs however reported that, "though in pen and paper target free approach (TFA) is there, but in reality, senior medical officers give them (ANMs) some target for female sterilisation and we have to cover them before the next common meeting".

- On fertility preference and sterilisation regret, some middle to old aged women told,

i. A family should have 6 children, since, even if one or two will be taken away by 'yama' (death god), there are still 4 children and that is OK for a family.

Where as one woman told,

ii. "Due to severe weakness, being frightened, I went for sterilisation operation, though I wanted to have one more daughter".

\section{CONCLUSION}

This paper analyses the women's behavioural factors with regard to impact on fertility. The behavioural factors of women such as smaller desired family size and longer perceived ideal birth interval has been consistently associated with lower fertility. For Scheduled caste population, the association of woman's correct knowledge about probable days of conception within menstrual cycle, with lower fertility gives impression that this knowledge may provide chance to the woman or couple to go for some kind of fertility control mechanism.

The verbatim and incidents presented in the paper give an impression that at one hand the child survival is at demand and in other hand there seem to have a need for access to controlled and intended fertility. 


\section{REFERENCES}

Andrews, Frank; Morgan, J. N. and Souquist, J. A.: Multiple Classification Analysis- A Report on a Computer Programme for Multiple Regression Using Categorical Predictors. University of Michigan, Institute for Social Research, Michigan (1973).

Bongaarts, J. and Potter, Robert G.: Fertility, Biology and Behaviour: Analysis of the Proximate Determinants, Academic Press, New York (1983).

Bongaarts, J.: The relative contribution of biological and behavioural factors in determining natural fertility: A demographic perspective, pp. 9-18. In: Ronald Gray, Henri Leridon and Alfred Spira (Eds.): Biomedical and Demographic Determinants of Reproduction. Oxford University Press, New York (1993).

Census of India, 1991: Special Tables for Scheduled Castes and Scheduled Tribes. Registrar General of India, New Delhi (1991).
Davis, Kingsley and Judith Blake: Social Structure and Fertility: An analytical Framework. Economic Development and Social Change, 4(3): 211-235 (1956).

Mari Bhat, P.N.: Priority area in demographic research. Journal of Institute of Economic Research, 28(1): 1-10 (1993).

Nag, Moni: Factors affecting Human Fertility in Nonindustrial Societies: A Cross-Cultural Analysis, Yale University Publication, U.S.A. (1962)

Page, H.J. and Lesthaeghe, R.: Child-spacing in Tropical Africa: Traditions and Change. Academic Press, New York. (1981).

Pillane, W.H.S. and Ryser, E.: Male Fertility Survey: Fertility Knowledge, Attitude and Practice of Married Men. Ballinger Publishing Company, Cambridge (1975).

Pressat, Roland and Wilson, Christopher: The Dictionary of Demography. Oxford, England; Blackwell Reference, New York (1985). 